Res Publica. Revista de Historia de las Ideas Políticas ISSN: 1576-4184

http://dx.doi.org/10.5209/RPUB.60858

\title{
Alemania y el complejo romano
}

\section{A propósito de Helmuth Plessner, La nación tardia: sobre la seducción política del espíritu burgués (1935-1959), Madrid, Biblioteca Nueva, 2017, 238 pp.}

Roberto Navarrete Alonso*

Desde la primavera de 2017, el lector en castellano tiene a su disposición, editada por Joachim Fischer y José Luis Villacañas, en traducción a cargo de Kilian Lavernia, La nación tardía: sobre la seducción política del espíritu burgués (19351959). Se trata de la gran obra, escrita desde el exilio, del filósofo, antropólogo y sociólogo alemán Helmuth Plessner (1892-1985). De este modo, prosigue la todavía escasa recepción del pensamiento plessneriano en nuestro país, limitada hasta hoy a las versiones castellanas de Límites de la comunidad (1924) y La risa y el llanto (1941), así como de la antología de textos publicada bajo el título Más acá de la utopía (1966) ${ }^{1}$. Permanecen aún sin verter a nuestra lengua, entre otros textos de este padre de la antropología filosófica, Macht und menschliche Natur (1931), así como su opus magnum, Die Stufen des Organischen und der Mensch (1928), en el que Plessner presenta su tesis acerca de la constitución fundamental del ser humano, a saber, la de su "posicionalidad excéntrica". La importancia de estas dos obras reside ante todo en la polémica que, de manera explícita en un caso, e implícita en el otro, Plessner mantiene en ellas con la analítica heideggeriana del Dasein, cuya entusiasta recepción en Alemania eclipsó casi por completo la recepción de Die Stufen, trabajo casi contemporáneo de Ser y tiempo (1927). En este sentido, el trabajo de Plessner anterior a La nación tardía, texto al que vamos a referirnos en estas páginas, señala

\footnotetext{
Universidad Complutense de Madrid roberto.navarrete.alonso@gmail.com

1 Cf. H. Plessner, Más acá de la utopía, trad. de E. Bueno, Alfa, Buenos Aires, 1978; Id. La risa y el llanto. Investigación sobre los límites del comportamiento humano, trad. de L. García Ortega, Madrid, Trotta, 2007; e Id., Límites de la comunidad. Crítica al radicalismo social, trad. de T. Menegazzi y V. Granado, Madrid, Siruela, 2012.

2 Cf. H. Plessner, "Macht und menschliche Natur. Ein Versuch zur Anthropologie der geschichtlichen Weltansicht”, en Gesammelte Schriften V, Franksurt Suhrkampa. M., 2015, pp. 135-234, así como Id., "Die Stufen des Organischen und der Mensch. Einleitung in die philosophiesche Anthropologie", en Gesammelte Schriften IV, Suhrkamp, Frankfurt a. M., 2003. Existe, no obstante, una versión española del primer apartado del capítulo séptimo de esta obra, dedicado a la ley de la excentricidad, en la revista Clínica y pensamiento 2 (2003) 7-26. La traducción corre a cargo de A. Gely Alonso.
} 
los límites del pensamiento de Heidegger, cuyos filosofemas han dominado la denominada como filosofía continental. Se trata, por cierto, de límites de naturaleza tanto teórica como práctica, es decir, política, lo cual reviste particular importancia en el contexto de surgimiento de las dos grandes obras de Plessner y Heidegger, a saber, la frágil República de Weimar.

En el momento en que Plessner escribió La nación tardia, cuya primera versión apareció en 1935 bajo el título El destino del espíritu alemán al final de su época burguesa, regían sin duda ya otras condiciones ${ }^{3}$. El ascenso al poder de Adolf Hitler en 1933 obligó a Plessner, Halbjude conforme a las categorías del nacionalsocialismo, a abandonar Alemania en dirección a los Países Bajos, tras un breve paso por Turquía. A partir de 1934, pudo impartir en la Universidad de Gröningen las lecciones que, un año más tarde, dieron lugar a la obra sobre la que versan estas páginas. El libro llegó a circular en Alemania, si bien al poco tiempo resultó prohibido por el régimen de Hitler, valdría decir que a pesar de que Plessner no hace una sola mención ni del nacionalsocialismo ni de su líder. No es un libro sobre el III Reich, en efecto, sino sobre las condiciones espirituales que, en su devenir, permitieron el triunfo, precisamente en Alemania, del nihilismo, así como la apelación a la desnuda voluntad de poder -en un gesto que se pretendió nietzscheano- como fundamento último de la política. Sólo en la versión de 1959, por tanto, ya bajo el título de $L a$ nación tardía, fue esta obra bien recibida en la joven República Federal, leída como el diagnóstico de un síndrome, el del retraso nacional alemán, al que el flamante federalismo constitucional venía a ofrecer remedio. Se trataba asimismo de un escrito sobre la culpa, redactado antes de que la culpa tuviese lugar: antes de que estallase la Segunda Guerra Mundial y antes de que comenzara a ejecutarse la terrible Endlösung de la cuestión judía en Alemania, por no decir en Europa - es decir, en la Europa ocupada o dependiente del III Reich, acaso con excepción de la Italia de Mussolini, que si bien era fascista nunca terminó por entregarse al racismo pseudocientífico, rasgo distintivo de la versión alemana del fascismo-.

La mirada que Plessner arroja sobre Alemania en La nación tardía es, por tanto, propia de un exiliado. En este sentido, la obra debe ser acaso leída como una aportación a la memoria histórica alemana en la línea de las propias de Hannah Arendt, Franz L. Neumann, Theodor W. Adorno, Thomas Mann, Bertolt Brecht o incluso Walter Benjamin y Erik Peterson, entre otros. Si bien es cierto que cabría compararla, por el hecho de ofrecer una ontología política del presente a partir de los impulsos procedentes de la esfera espiritual, con obras anteriores a 1914, en especial con Weltbürgertum und Nationalstaat (1908) de Friedrich Meinecke, así como con la poco conocida obra de su discípulo Franz Rosenzweig, Hegel und der Staat (publicada en 1920, pero concluida antes del estallido de la Gran Guerra) ${ }^{4}$. Esta comparación es de especial relevancia si se entiende la Segunda Guerra Mundial como un segundo episodio de guerra civil europea que no cabe ser entendido sin el primero, a pesar de que éste tienda a ser olvidado o, cuando menos, minusvalorado en comparación con lo ocurrido entre 1939 y 1945 -con toda probabilidad como consecuencia de la

Cf. H. Plessner, Das Schicksal deutschen Geistes im Ausgang seiner bürgerlichen Epoche, Zürich-Leipzig, Niehans, 1935. Para una biografía intelectual de Plessner, cf. C. Dietze, Nachgeholtes Leben. Helmuth Plessner (1892-1985), Göttingen, Wallstein, 2006.

4 Cf. F. Meinecke, Weltbürgertum und Nationalstaat. Studien zur Genesis des deutschen Nationalstaates, München-Berlin, Oldenbourg, 1908, así como F. Rosenzweig, Hegel und der Staat, München-Berlin, Oldenbourg, 1920 . 
absolutización del exterminio perpetrado por el III Reich como acontecimiento que parte en dos la historia o, como lo expresa Enzo Traverso, como religión civil de nuestro tiempo ${ }^{5}$. No obstante, existe una diferencia fundamental entre las respectivas aproximaciones de Meinecke y Plessner al devenir político-espiritual de Alemania: el primero, embebido en la atmósfera nacionalista del Reich bismarckiano y a diferencia, por cierto, de Rosenzweig, entendía aún el Estado nacional como el destino histórico de toda nación que se preciase.

La Verspätung a la que se refiere Plessner, es decir, el retraso nacional de Alemania, fue entendido por Koselleck en este sentido, a saber, como si el autor de $L a$ nación tardía hubiese querido en algún sentido denunciar la tardanza del pueblo alemán en relación a su meta histórica o bien relación a otras naciones europeas ${ }^{6}$. Sin embargo, como muestra José Luis Villacañas en su excelente epílogo a La nación tardía, no hay en Plessner rastro alguno de teleología ni de filosofía de la historia ${ }^{7}$. El retraso nacional de Alemania, según Plessner, tiene que ver con el hecho de que, para cuando la realidad estatal-nacional llegó a Alemania, los ideales, el espíritu -primero humanista, después ilustrado y, ante todo, francés- sobre el que pudo erigirse el Estado nacional alemán no pudo ya encontrar un hogar en la burguesía alemana. Lo cual se explica, en particular, por el profundo sentimiento antifrancés del que surgió el Reich de Bismarck, y, en general, por el hecho de que, a finales del XIx, en realidad, la Modernidad daba ya muestra de claros síntomas de cansancio. La modernización de Alemania, por tanto, pudo ser económica, e incluso política, pero esto último sólo desde un punto de vista formal: un Estado nacional desprovisto de idea en tanto que desprovisto de una nación que fuese portadora de esa idea. Se impuso una forma política estatal-nacional sobre un pueblo que no había alcanzado la forma nacional característica de la Francia de finales del siglo anterior. De manera que incluso cabría pensar el retraso como consecuencia de un desajuste temporal entre la forma estatal-nacional y la inexistente realidad nacional. $\mathrm{O}$, en otros términos, podría decirse que el Estado nacional llegó a Alemania demasiado pronto, incluso que no debió haber llegado nunca, si el término de comparación lo ofrece, no la homogeneizadora y centralizadora forma nacional francesa, sino la heterogeneidad de los pueblos alemanes - de lengua alemana- realmente existentes.

Como sostiene Villacañas, a estos pueblos alemanes no les convendría la forma política estatal-nacional, sino una de carácter federal. Es ésta, en realidad, y no la nación, la que llegó demasiado tarde a Alemania. No lo hizo hasta 1990, cuando por lo demás ya era impensable que pudiese albergar en su seno lo que en todo caso podría considerarse la nación alemana, en el sentido del conjunto de los pueblos alemanes, integrado no sólo por los incluidos hoy en las fronteras de la República Federal de Alemania, sino también por los de la actual República -también Federal- de Austria, por la Suiza germanoparlante e incluso por algunos territorios que en 1871 formaban parte de los dominios de los Habsburgo -la Bohemia de Kafka, Hugo Bergmann o Max Brod, sin ir más lejos-. No es el caso, por tanto, que la nación alemana llegase

Cf. E. Traverso, El final de la modernidad judía. Historia de un giro conservador, trad. de G. Muñoz, Valencia, Universitat de València, 2013, pp. 203 ss.

6 Cf. R. Koselleck, "Deutschland «eine verspätete Nation»?" en Zeitschichten. Studien zur Historik, Frankfurt, Suhrkamp, 2000, pp. 359-379.

7 Cf. J. L Villacañas, "Epílogo. La nación tardía y nosotros. El sentido de un concepto", en H. Plessner, La nación tardía. Sobre la seducción política del espíritu burgués (1935-1959), ed. de J. Fischer y J. L. Villacañas, trad. de K. Lavernia, Madrid, Biblioteca Nueva, 2017, pp. 217 ss. 
tarde a la historia, sino que en realidad nunca ha llegado: el II Reich no fue un Estado nacional alemán, sino un Estado nacional prusiano impuesto sobre una parte de los pueblos alemanes, que conformaron su Staatsvolk; el III Reich fue un Estado racial, no nacional, también de raíz prusiana, que por su desmedida ambición -política, burocrática, militar y capitalista- fue capaz de imponerse sobre un conjunto más amplio de los pueblos alemanes; la República Federal, por último, no es tampoco un Estado nacional en sentido estricto - como ha querido serlo España desde 1939, con los problemas que esto acarrea, y que no cabe encontrar en la actual Alemania-, pues la que podría ser la nación alemana permanece dispersa entre diversas realidades estatales, de manera que el compromiso en que se sustenta es mantenido sólo por una parte de los pueblos alemanes.

"Nación" significa pueblo en tanto que fuerza democrática efectiva, es decir, revolucionaria: titular efectivo (de facto) y no sólo formal (de iure) del poder constituyente. Tal cosa no ha existido en Alemania, ni en Austria: las revoluciones de 1848 fracasaron y, en el mejor de los casos, dieron lugar a reformas efectuadas desde arriba. Toda revolución ha sido, en estos países, de carácter pasivo: a iniciativa de las élites y, después de 1945, a iniciativa de los vencedores. También éstos determinaron la bipartición política de la nación cultural alemana, es decir, impidieron, en aras del equilibrio territorial intraeuropeo, que la estructura federal abarcase el conjunto de los pueblos germánicos: aunque por muchas razones de índole cultural -lingüística y religiosa-, por ejemplo, Baviera sea más austriaca que alemana. Nada de esto, en todo caso, permite hablar de un Sonderweg alemán: no hay una vía específica alemana, porque no hay una vía normal, sino tan solo vías normalizadas, es decir, convertidas en patrón de medida de todas las demás por medio de una operación de carácter ideológico en la que, de nuevo, el resultado de las catástrofes europeas del siglo pasado, las dos guerras mundiales, es determinante. La liberación de Europa sería, eo ipso, una normalización de Alemania (de la occidental, en un primer momento y, tras la convergencia económica y el final de la URSS, también de la Alemania oriental), a saber, su adaptación a los modelos político-nacionales triunfantes, con la consiguiente escisión, a todas luces artificial, entre las naciones alemana y austriaca -aun respetando, en su interior, la estructura federal-. Solo la institucionalización de un determinado modo de recordar la historia acontecida permite hablar de un Sonderweg alemán.

Por supuesto que la cuestión territorial, como la cuestión religiosa, confiere especificidad a la historia de Alemania, pero esa especificidad, permítaseme la redundancia, no es menos específica que la especificidad «normal» de Francia o de Inglaterra, por no hablar de las de Italia, Rusia o, por supuesto, España -donde la especificidad religiosa de Alemania viene sustituida por la especificidad lingüística de los pueblos españoles-. La particularidad alemana, entonces, como sostiene Wolf Lepenies, es una de carácter disminuido ${ }^{8}$. Plessner compartiría esta tesis. No en vano, al comienzo del tercer capítulo de La nación tardía, titulado "No Estado, sino pueblo", se refiere a Alemania, España e Italia como tres grandes pueblos europeos que comparten una cierta especificidad -que en esa misma medida no lo es tanto-, a saber, el que "no han

\footnotetext{
Cf. W. Lepenies, La seducción de la cultura en la historia alemana, trad. de J. Blasco, Madrid, Akal, 2008, pp. 13 ss.

9 Cf. H. Plessner, La nación tardia, op. cit., pp. 73-83.
} 
participado en el desarrollo, desde el siglo XVII, de la moderna conciencia de Estado"10, como consecuencia de lo que Plessner llama "complejo romano" lo con el catolicismo y la consiguiente tensión entre lo estatal-prusiano-protestante y lo imperial-austriaco-católico. Frente al concepto "nación", propio de los modelos estatales inglés y francés, en estos países cobró especial acento el término "pueblo". Plessner no desarrolla el paralelismo, pues el objeto de su libro es otro, pero sí lo hace, de manera magistral, Villacañas, en el ya referido epílogo a La nación tardía, en el cual presenta una decidida crítica a la interpretación del proceso nacional español por parte de José Ortega y Gasset, a partir de la sin duda más que discutible unidad de formas de vida de los pueblos españoles simbolizada por la unidad de lengua ${ }^{12}$.

En el caso de Alemania, la cuestión determinante no es desde luego lingüística, sino religiosa. La tesis de Plessner respecto del devenir político de los pueblos germánicos tiene como núcleo fundamental el papel desempeñado en él por el luteranismo, así como por las consecuencias derivadas de éste, que el autor de La nación tardía expresa a partir de los conceptos de "religiosidad intramundana" (Weltfrömmigkeit), "mundanización" (Verweltlichung) e "interioridad" (Innerlichkeit). La referencia aquí, en realidad, no es acaso tanto Lutero per se, cuanto, en lo que se refiere al ámbito filosófico, Hegel, por medio de su interpretación de la Modernidad como la realización histórica del cristianismo en el mundo, es decir, su mundanización, por medio del Estado. Al introducir una relación dialéctica entre mundo y espíritu, Hegel disolvía el esquema agustiniano-católico de las dos ciudades, que durante siglos había aportado el fondo histórico-cultural de Occidente: salus y fides pasaban a coincidir, en la medida en que se afirmaba la identidad de lo real-efectivo y de lo racional-espiritual, que se desplegaría en la historia y no permanecería esperando al final de los tiempos. El movimiento dialéctico del que la Modernidad es resultado consistiría así en una mundanización de lo sagrado y una sacralización de lo temporal en la que el Estado aparece como instancia de mediación ${ }^{13}$. Sin ser geistlich (eclesiástico), es geistig (espiritual): la Iglesia no posee el monopolio de lo espiritual y el Estado -al menos el Estado racional o ético- no es sin más una institución secular, sino la realización del Espíritu en el mundo.

Una concepción tal favorece el refugio en la interioridad y en la cultura, la indiferencia por tanto respecto de la política, que parece ser cosa del Espíritu y su despliegue. Pero también el respeto, precisamente, religioso, por la autoridad del Estado, así como la decidida disposición a sacrificarse por él, toda vez que en él se juega el destino histórico-universal del pueblo y, en realidad, su salvación, dado el carácter de tribunal universal, o de juicio final, que la historia adquiere desde esta perspectiva. Cuestionar la autoridad política, no entregarse a ella, como ya Lutero defendió para distanciarse de las revueltas campesinas lideradas por Münzer, significa en último término desobedecer a Dios mismo, ya que éste, en conformidad con lo que se dice en el capítulo 13 de la Carta a los Romanos, es una autoridad querida por Dios, a la que el creyente, por tanto, debe someterse: no sólo por temor al castigo, sino también en conciencia. La legitimidad de la resistencia frente al Estado queda negada, en definitiva, desde el mismo momento en que la diferencia entre lo espiri-

\footnotetext{
Ibidem, p. 73.

Ibidem.

Cf. J. L. Villacañas, "Epílogo. La nación tardía y nosotros. El sentido de un concepto”, pp. 212 ss.

Cf. A. Rivera, "La secularización después de Blumenberg", Res Publica 11-12 (2003) 97-98.
} 
tual y lo terrenal no coincide con la diferencia institucional entre Iglesia y Estado, como había querido Agustín con el fin de poner límites a la potestas imperial, sino que en el fondo dicha diferencia queda suturada y, así, queda a su vez eliminado todo resto -tanto por el lado del mundo, como del espíritu-desde el cual poder cuestionar la autoridad estatal con eficacia ${ }^{14}$.

A pesar de la centralidad que el luteranismo tiene para el diagnóstico plessneriano del síndrome de la nación tardía - presente ya, por lo demás, en su crítica al radicalismo en Limites de la comunidad ${ }^{15}$, en su obra de 1935 Plessner se detiene asimismo en el impacto de la Revolución Industrial sobre la burguesía alemana: el alcance de la economización de la existencia humana que tuvo en Alemania la revolución del proceso mismo de trabajo, gracias a su tecnificación, con la aceleración del progreso que ésta supone. Esto tiene que ver sin duda con lo que Adorno y Horkheimer expusieron en 1944 en su Dialéctica de la Ilustración ${ }^{16}$, a saber, con la formalización de la razón, privada de toda sustancia y puesta al servicio del capitalismo, que a su vez no es tampoco un fin, sino, a su vez un instrumento: una herramienta en manos de un Estado que no se quiere más que a sí mismo la conservación y ampliación de su propio poder, al margen de toda idea. Esta funcionalización del saber tiene que ver sin duda con el proceso de secularización como desencantamiento del mundo. Weber mostró la afinidad existente entre La ética protestante y el espíritu del capitalismo (1904-1905), como sabemos ${ }^{17}$. El triunfo de la ratio, en el sentido del cálculo de lo real, mantiene una relación de proporcionalidad directa con la falta de tradición, en el sentido de un fundamento sustancial de lo real, ya fuese éste provisto por el Dios premoderno, por la metafísica o por la moral.

La economización y la tecnificación, el industrialismo, cala más hondo allí donde no hay un sustrato espiritual que atravesar, que sea capaz de poner límites al dominio que se ejerce sobre el mundo. Una gran potencia sin idea de Estado es por tanto el hábitat perfecto para la economía, que como el Estado sólo quiere aumentar su capacidad: productiva en un caso, coercitiva en el otro. De ahí la íntima afinidad existente entre el Estado totalitario y el capitalismo monopolista, como mostró Neumann en su Behemoth $^{18}$. Y de ahí también que esta combinación fuese el resultado, en Alemania, de la profunda crisis económica en que se vio envuelta como consecuencia de la derrota militar en la Primera Guerra Mundial y las reparaciones de guerra impuestas en Versalles. Un Estado desprovisto de idea quiere sólo expandir su poder, lo cual repercute de manera positiva en la economía; ésta se desmorona en el momento en que el Estado es derrotado. Allí donde el homo oeconomicus no tiene nada a lo que aferrarse, como era el caso de la burguesía alemana, el efecto de una gran crisis económica se traduce en el imperioso deseo de recuperar la fuerza estatal, capaz de poner en marcha la maquinaria del capitalismo. De manera inmediata, una de las causas del colapso de Weimar fue la crisis económica y la seducción que un Estado

14 El propio José Luis Villacañas ha expuesto de manera espléndida la posición agustiniana en su Teología politica imperial y comunidad de salvación cristiana. Una genealogía de la división de poderes, Madrid, Trotta, 2016, pp. 515 ss.

15 Cf. H. Plessner, Limites de la comunidad, op. cit., pp. 36 ss.

16 Cf. Th. W. Adorno y M. Horkheimer, Dialéctica de la Ilustración. Fragmentos filosóficos, trad. de J. J. Sánchez, Madrid, Trotta, Madrid, 2006.

17 Cf. M. Weber, La ética protestante y el “espiritu” del capitalismo, trad. de J. Abellán, Madrid, Alianza, 2016.

18 Cf. F. L. Neumann, Behemoth. Pensamiento y acción en el nacionalsocialismo 1933-1945, trad. de V. Herrero y J. Márquez, Barcelona, Anthropos, 2014. 
como el de Hitler supuso para la burguesía. No obstante, el problema de fondo era el desarraigo espiritual del Estado: el carácter apolítico de la cultura y de la burguesía alemanas, así como su inmersión en un proceso de mundanización sin límites que eleva la economía y la técnica, puros instrumentos, a la condición de valores absolutos a los que el Estado sirve; su carencia de un espíritu al que sirviera el Estado y, a su vez, la economía y la propia técnica: la falta de sentido, en último término, como consecuencia del carácter abscóndito del Dios del luteranismo, que deja el mundo por completo en manos de los hombres, a la entera disposición de éstos.

En este contexto, Plessner denuncia que la filosofía alemana, la más alta creación del espíritu alemán, fracasó de modo estrepitoso en su compensatoria búsqueda de sentido, en especial de Hegel en adelante. El salto del autor de la Fenomenología del Espíritu a Marx resultó determinante, pues aunque en él desaparece el Geist, no lo hace en cambio la "fe en la redención"19, como indica Plessner. Permanece la materialidad de la historia universal, que viene a sustituir a la especulación filosófica del mismo modo que antes la filosofía (la metafísica) había sustituido a la teología, y permanece la búsqueda de sentido, ya no en algo que trascienda la historia, aunque se realice en ella, sino en la "historia intramundana"20, usando de nuevo una expresión de Plessner. La senda abierta por Marx, a diferencia de la de Kierkegaard, condujo hacia el "más acá oculto" 21 que debe ser desvelado: hacia la historia, en primer lugar, primero revestida de filosofía y después liberada de ella, y hacia el mundo de las ciencias sociales y de las ciencias biológicas ${ }^{22}$. La idea capital es siempre la misma, a saber, la de evolución: evolución de la historia, de las sociedades y, por último, de la vida natural, en especial de las razas humanas. En último término, el desmoronamiento de la autoridad religiosa, espiritual e histórica, deja la existencia natural como único apoyo, como fuente de sentido en un mundo por completo desprovisto de él. Lo cual tiene que ver con el problema del mal y su justificación, es decir, con la teodicea: la noción de evolución, incluida su variante biológico-racial, permite justificar la sucesión de catástrofes en la historia como algo necesario, requerido por un proceso evolutivo que se ha convertido en un fin en sí mismo. La biologización de la idea de evolución surge, como explica Plessner, del desmoronamiento de la autoridad, primero, supramundana (divina), y, en segundo lugar, de la intramundana: la racionalidad, de alcance universal, que todavía en Marx era inherente a la historia y a las sociedades humanas. Caídas las fuentes tradicionales de autoridad, no quedaba otra cosa en Alemania que la nuda existencia y la decisión en aras de su mantenimiento y fortalecimiento, es decir, una decisión desprovista de todo criterio que no sea la propia existencia biológica. A su servicio se pone la técnica, la economía y la maquinaria estatal, en busca de un espacio, no en vano, vital.

La tesis de Plessner es en definitiva que la filosofía alemana fue derrotada por sí misma, por su propia desmesura: se entregó a las ciencias y acabó capitulando ante la política, ante la totalidad, en lugar de aspirar al infinito, por decirlo empleando el título de la célebre obra de Lévinas ${ }^{23}$. La filosofía fracasa como compensación

\footnotetext{
H. Plessner, La nación tardía, op. cit., p. 119.

Ibidem, p. 120.

Ibidem, p. 119.

22 También Karl Löwith encontró en Kierkegaard y Marx las dos modalidades de superación de la filosofía hegeliana. Cf. K. Löwith, De Hegel a Nietzsche. La quiebra revolucionaria del pensamiento en el siglo XIX, trad. de E. Estiú, Buenos Aires-Madrid, Katz, 2008.

23 Cf. E. Lévinas, Totalidad e infinito. Ensayo sobre la exterioridad, trad. de M. García-Baró, Salamanca, Sígueme, 2012 .
} 
de la falta de políticas liberales, es decir, en el propósito de garantizar una esfera de libertad para el hombre individual. Esto es lo que nos muestra la dialéctica de la Ilustración alemana. La cuestión es, quizá, que no es ese el papel que corresponde a la filosofía: un rol compensatorio, pero tampoco debe quedar reducida a la política, ni ponerse sin más a su servicio. Plessner habla en este sentido de la filosofía como reservatio mentalis, cuyo papel sería "salvaguardar la dignidad y el carácter irrenunciable del ser que se posee a sí mismo como sí mismo" (p. 185). Esto no se traduce en quietismo alguno, sino en una negación de la capacidad de la política para ordenar las comunidades humanas de una vez por todas: de introducir una verdadera eternidad en el tiempo, de acuerdo con el carácter excéntrico de la naturaleza humana, es decir, con la inescrutabilidad o insondabilidad del ser humano, que permanece siempre como una cuestión abierta, nunca dirimible de manera definitiva. Al ser humano le es constitutiva su pertenencia a una comunidad, a un ámbito de familiaridad, así como su apertura a lo extraño, a lo otro de sí.

Es la propia constitución fundamental del ser humano la que pone límites a la comunidad, tanto étnico-nacional como universal-internacional, por medio de la creación artificial de la esfera pública a la que el radicalismo, inspirado en Alemania por el luteranismo, había dado por completo la espalda. Se trata de la esfera de la responsabilidad, que pone freno, en sentido weberiano, a los desmanes a los que puede conducir las convicciones comunitaristas que acechan siempre, pero en especial en tiempos de crisis. La edición en castellano de La nación tardía de Plessner tiene por esta razón una enorme actualidad, acaso en especial en nuestro país, por la mencionada afinidad entre el devenir político de los pueblos germánicos y de los de las Españas. Tanto a unos como a otros conviene, por su carácter heterogéneo, una forma política federal, no estatal-nacional, como hemos mencionado. El problema territorial de nuestro Estado cobra especial intensidad, empero, en momentos de crisis económica e institucional, como los que vivimos en la actualidad. Por igual motivo, la responsabilidad política es si cabe más acuciante en estas situaciones, en las que adquiere especial vigor la tendencia a dar rienda suelta a las convicciones comunitaristas, que hoy adoptan la forma de populismos: étnico-nacionales, reaccionarios, y, también, "de izquierdas". De ahí que debamos aprender de Weimar. Su Constitución adolecía de una falla constitutiva, de tal manera que su fracaso final quizá no fuese otra cosa que aquello a lo que desde el principio estaba destinada. Fue una pura contingencia histórica que los nacionalsocialistas llegaran al poder: pudieron haberlo hecho los comunistas y pudo haberlo hecho asimismo la denominada Revolución Conservadora. Pero, en sí mismo, el colapso de la República de Weimar no fue una casualidad de la historia, sino la consecuencia -casi habría que decir "lógica"- de la estructura misma del texto constitucional y del orden institucional de él resultante, así como de la sociología sobre la que se erigía y en el contexto de una profunda crisis económica - primero alemana, consecuencia de las reparaciones de guerra, y después global-. Weimar no fue suficientemente republicana, es decir, weberiana, ni plessneriana.

Debemos arrojar nuestra mirada sobre aquella época, pero esta mirada, que es histórica en la medida en que se dirige al pasado, debe ser puesta al servicio de la comprensión de nuestro presente. Dada la actual coyuntura económica y política, tenemos mucho que aprender de aquella época, de la que Plessner nos ofrece un testimonio extraordinario, tanto en La nación tardía como en Límites de la comunidad y en Macht und menschliche Natur, cuya traducción al castellano es ya urgente. Formulado de manera muy sumaria, la cuestión fundamental es la de resistir ante 
toda tendencia homogeneizadora de los agrupamientos humanos -sea cual sea el factor de homogeneización, pero en especial cuando lo es la etnia- como la que hoy representan los populismos en Europa. Al mismo tiempo, se trata de resistir frente a la erosión política y frente a la desagregación que produce y fomenta el neoliberalismo. Para lo cual, conforme a la enseñanza de Plessner -y de Weber-, sería necesario hacer pie, con firmeza, en la tradición republicana, como único camino para combatir la idiocia, tanto populista como neoliberal. El republicanismo nos protege de la idiotez apolítica de la economía, así como de la idiotez ultrapolítica de la comunidad. Asume, o puede asumir al menos, sus propios límites, y abandonar la aspiración a un cierre hegemónico que termine por anquilosarse en beneficio de unos pocos y en detrimento de lo común. Lo cual vale tanto para los Estados como para las federaciones de Estados y, por tanto, para Europa, que debe ser concebida, desde un punto de vista político, como el resultado de un compromiso basado en la corresponsabilidad de las partes y en la apertura a la renovación. 